\title{
CARÁCTER SEMIFORMATIVO DE LOS MEDIOS AUDIOVISUALES. LAS INVESTIGACIONES EMPÍRICAS DE THEODOR W. ADORNO SOBRE LA TELEVISIÓN
}

\author{
MATEU CABOT \\ Universitat de les Illes Balears
}

La televisión presenta un problema cultural y pedagógico. Th. W. Adorno

\begin{abstract}
RESUMEN: En este artículo analizamos los resultados de la investigación empírica de Theodor W. Adorno sobre la televisión. Dicha investigación fue parte del conjunto de estudios sobre la cultura de masas que realizó durante el período de emigración en los Estados Unidos. Con la ayuda de conceptos psicoanalíticos descubrió una serie de estructuras presentes en los diversos productos de la industria cultural que caben bajo el concepto general de semiformación. Con él pretendía, además de recordar el carácter ilusorio de la satisfacción producida por el consumo cultural, mostrar los mecanismos con los que era posible crear una ilusión de realidad. Dichos mecanismos son diferentes de aquellos que permitieron la formación en los primeros tiempos del capitalismo y posiblemente incompatibles con instituciones formativas creadas en aquel momento.
\end{abstract}

PALABRAS CLAVE: adorno, televisión, teoría crítica, cultura de masas, estética, semiformación

\section{Media's Half-Formative Nature. Theodor W. Adorno's Empirical Research On TV}

ABSTRACT: We analyze in this paper the results of Theodor W. Adorno's empirical research on television. This research was part of a the studies on mass culture made during the time he lived in the United States. With the help of psychoanalytic concepts he discovered a number of structures in several products of the culture industry that fall under the general concept of half-formation. With this concept he wanted to remember the illusory nature of the satisfaction produced by cultural consumption and to show the mechanisms by which it was possible to create an illusion of reality. These mechanisms are different from those that allowed the formation in the early stages of capitalism and are possibly incompatible with training institutions created at that time..

KEY WORDS: adorno, television, critical theory, mass culture, Aesthetics, Half-formation.

\section{INTRODUCCIÓN}

Es un lugar común reprochar a Adorno su desdén por la cultura de masas ${ }^{1}$, pero sería más correcto y exacto decir que mantuvo una posición teórica muy

1 Vid. Muñoz, B., Theodor W. Adorno: Teoría crítica y cultura de masas. Madrid, Fundamentos, 2000, pp. 205-222. El título del capítulo al que nos referimos se titula: «Tópicos sobre la Teoría Crítica y la obra de Th. W. Adorno». 
crítica, fundamentada en una investigación muy amplia, tanto en el tiempo como en el objeto, posición crítica que, por otra parte, comparte con gran variedad de personas, incluso stars de la cultura de masas ${ }^{2}$. En este texto queremos seguir la investigación adorniana sobre un medio emergente en su momento pero hoy central en la cultura de masas y en la vida cotidiana, la televisión, con el objetivo de esclarecer su incidencia en los procesos de subjetivación y socialización, especialmente en aquellos que afectan directamente al proceso educacional de los individuos.

A partir de su llegada a Estados Unidos en 1937 Theodor W. Adorno investigó la cultura de masas en contacto directo con ella. Hasta su regreso definitivo a Alemania en 1953 participó activamente en investigaciones empíricas sobre cuestiones particulares de la radio, el cine, la música grabada o las revistas ilustradas ${ }^{3}$. En Dialéctica de la Ilustración, finalizada en 1944, él y Max Horkheimer trataron de la cultura de masas en el capítulo titulado «La industria cultural. Ilustración como engaño de masas» ${ }^{4}$. Años más tarde, al principio de dos conferencias radiadas en 1963 por la Hessischen Rundfunk y publicadas posteriormente bajo el título «Résumé über Kulturindustrie», explicó el motivo del cambio terminológico: «En nuestros borradores hablábamos de "cultura de masas". Pero sustituimos esta expresión por "industria cultural" para evitar la interpretación que agrada a los abogados de la causa: que se trata de una cultura que asciende espontáneamente desde las masas, de la figura actual del arte popular» ${ }^{5}$.

Adorno relató, en el texto "Wissenschaftliche Erfahrungen in Amerika» de $1968^{6}$, la experiencia que supuso participar, entre 1937 y 1952, en proyectos de investigación social aplicada, siempre vinculados al sistema académico norteamericano y financiados, directa o indirectamente, por la industria del

2 «La tecnología ha cambiado cómo suena la música, cómo se compone cómo la experimentamos. También ha inundado de música al mundo. El mundo está saturado de (sobre todo) sonidos grabados. Antes teníamos que pagar por la música o debíamos hacerla nosotros mismos; tocarla, escucharla y experimentarla era excepcional, era una experiencia rara y especial. Ahora escucharla es universal, y el silencio es la rareza por la que pagamos y que saboreamos», Byrne, D., Cómo funciona la música. Trad. de M. Viaplana. Barcelona, Random House, 2014, p. 145. David Byrne es, además de escritor, voz cantante y guitarrista de la banda británica Talking Heads y, según la revista Rolling Stone, figura en la lista de los «100 Greatest Artists of All Time».

3 Vid. JAY, M., La imaginación dialéctica. Una historia de la Escuela de Frankfurt (19231950). Trad. de J. C. Grutchet. Madrid, Taurus, 1974, caps. VI-VII. Claussen, D., Theodor W. Adorno. Uno de los últimos genios. Trad. V. Gómez. Valencia, PUV, 2006, cap. 4.

4 Horkheimer, M.; Adrono, Th. W., Dialektik der Aufklärung. Philosophische Fragmente, recogido en: Adorno, Th. W., Gesammelte Schriften. Frankfurt, Suhrkamp, 1981, vol. 3, pp. 141-190. En adelante esta edición será citada con las siglas GS seguidas por el número de volumen y de página.

5 Adorno, Th. W., «Resumé über Kulturindustrie», GS 10.1, p. 337. Cf.: Kellner, D., «Theodor W. Adorno and the Dialectics of Mass Culture», en: Gibson, N.; Rubin, A. (eds.), Adorno. A Critical Reader, Oxford, Blackwell, 2002.

6 Adorno, Th. W., «Wissenschaftliche Erfahrungen in Amerika», GS 10.2, pp. 702-738. 
sector implicado. De la industria emanaban las directrices que se establecían en el contrato de financiación del proyecto, que eran tanto directas (definiendo los objetivos concretos de la investigación), como indirectas (un método de investigación que permita cuantificar los resultados). Esta imbricación de la empresa y la universidad permitía a los investigadores un acceso privilegiado a materiales de primera mano; en primer lugar de la propia industria cultural, la del cine, la radio, la televisión y los demás productos culturales, pero también de la administración gubernamental, interesada muy pronto por las posibilidades de esos medios para influir sobre los ciudadanos. Como consecuencia de los objetivos pretendidos, el método de investigación seguía el modelo que posteriormente se llamó "administrative research» ${ }^{7}$. Las dificultades de Adorno para encajar en este sistema eran evidentes: nunca antes había realizado investigación sociológica empírica y debía, pues, construir un método propio que, por una parte, profundizara críticamente en el objeto de estudio y, por otra parte, pudiera amoldarse y sobrevivir dentro del sistema de investigación. Como recordó posteriormente, la investigación sociológica se organizaba para responder a «la necesidad que tienen las grandes empresas de planificación de ventas, con la investigación de mercados y opinión enfocada al comercio», incluyéndose también en este ámbito de trabajo «los fenómenos de la moderna comunicación de masas (cine, prensa, radio, televisión, etc.)» ${ }^{8}$.

\section{LA DÉCADA AMERICANA DE AdORNO y ALGUNOS DE SUS RESUltados teóRICOS}

En el otoño de 1937 Max Horkheimer, ya establecido en Nueva York, telegrafió a Theodor W. Adorno, entonces exiliado en Inglaterra, con la posibilidad de emigrar a Estados Unidos para incorporarse de inmediato a un proyecto de investigación de la radio9. Las reticencias iniciales de Adorno son vencidas por la necesidad de asegurarse la supervivencia en América, fuera del alcance del desastre que ya estaba ocurriendo en Alemania, y por la confianza de que «mi amigo no me habría hecho esta propuesta si no hubiera estado convencido

7 Fue el sociólogo Paul Lazarsfeld quien expuso los principios de este tipo de investigación sociológica empírica en la introducción a un número especial de Studies in Philosophy and Social Science de 1941, la revista en Estados Unidos del Institut für Sozialfoschung, dedicado a la «ciencia de la comunicación»: LAZARSFELD, P. F., «Remarks on Administrative and Critical Communication Research», in: Studies in Philosophy and Social Science, 9 (1941), pp. 2-16. Sobre la Lazarsfeld vid. Picó, J., «Teoría y empiría en el análisis sociológico: Paul F. Lazarsfeld y sus críticos», Papers de Sociologia, Barcelona, 54, 1998, pp. 9-48. La posición de Adorno ante este tipo de investigación empírica queda recogida en: Aorno, Th. W.; Décamps, J.; Herberger, L. et al., «Empirische Sozialforschung», in: Handwörterbuch der Sozialwissenschaften, 6. Lieferung, Stuttgart u.a. 1954, pp. 419-432. Después en GS 9.2, pp. 327-359.

8 Adorno, Th. W., «Empirische Sozialforschung», GS 9.2, p. 331.

9 Adorno, Th. W., «Wissenschaftliche Erfahrungen in Amerika», GS 10.2, p. 703. 
de que un filósofo como yo podía hacerse cargo de esta tarea», aunque él mismo confesaría años después que «yo no estaba muy preparado para ella» ${ }^{10}$. El proyecto aludido era el Princeton Radio Research Project, dirigido por Paul Lazarsfeld, financiado por la Rockefeller Foundation y cuyo objetivo quedaba delimitado explícitamente en el contrato entre la fundación financiadora y la Office of Radio Research, convertida más tarde en Bureau of Applied Social Research, de la que dependía académicamente el proyecto, primero adscrita a la Princeton University, y, a partir de 1939, a la Columbia University en Nueva York.

A pesar de las discrepancias teóricas y la falta de sintonía con la orientación del proyecto ${ }^{11}$, toda vez que «las investigaciones tenían que moverse en el marco del sistema radiofónico comercial establecido en los Estados Unidos» ${ }^{12}$, el resultado teórico de la colaboración se substanció en textos de enorme valía, empezando por «Über den Fetischcharakter in der Musik und die Regression des Hörens ${ }^{13}$, del cual escribió, en el prólogo a la tercera edición (1963) de Disonancias. La música en el mundo administrado, que «fue el primer precipitado de las experiencias norteamericanas del autor, cuando éste dirigió la sección musical del Princeton Radio Research Project» ${ }^{14}$. En el prólogo de 1948 a Filosofía de la nueva música escribió acerca del mismo texto: «Su intención era la de exponer el cambio de función de la música de hoy día; señalar las modificaciones internas que los fenómenos musicales en cuanto tales sufren al subordinarlos a la producción comercializada de masas y, al mismo tiempo, indicar cómo ciertos desplazamientos antropológicos en la sociedad estandarizada penetran hasta la estructura de la audición musical» ${ }^{15}$. Otros textos elaborados para el proyecto aparecieron posteriormente en Current of Music. Elements of Radio Theory ${ }^{16}$, y otros aparecieron en otros volúmenes, como el texto «Sobre la utilización musical de la radio», incluido en El fiel correpetidor ${ }^{17}$, o el titulado «Musik im Rundfunk. Fragen und Thesen ${ }^{18}$.

10 AdoRno, Th. W., «Wissenschaftliche Erfahrungen in Amerika», GS 10.2, p. 704. («Yo ni siquiera sabía qué es un proyecto radiofónico», confiesa Adorno.)

11 Cf. LazArsfeld, P. F., "An episode in the history of social research: a memoir», in: Kendall, P. (ed.), The Varied Sociology of Paul Lazarsfeld. New York, Columbia University Press, 1982, pp. 11-73. SupA, D. W., «The Origins of Empirical Versus Critical Epistemology in American Communication». American Communication Journal, 2009, Vol. 11, n ${ }^{\circ} 3$. MorRIson, D., «Kultur and Culture: The Case of Theodor W. Adorno and Paul F. Lazarsfeld», Social Research, 45, 1978, pp. 331-345.

12 Adorno, Th. W., «Wissenschaftliche Erfahrungen in Amerika», GS 10.2, p. 707.

13 Adorno, Th. W., «Über den Fetischcharakter in der Musik und die Regression des Hörens», GS 14, pp. 14-50.

14 Adorno, Th. W., «Über den Fetischcharakter in der Musik und die Regression des Hörens», GS 14, p. 9.

15 Adorno, Th. W., Philosophie der neuen Musik, GS 12, p. 9.

16 Adorno, Th. W., Current of Music. Elements of Radio Theory, ed. Hullot-Kentor, R., Frankfurt, Suhrkamp, 2006.

17 Adorno, Th. W., «Über die musikalische Verwendung des Radios», GS 15, pp. 369-401.

18 Adorno, Th. W., GS 19, pp. 97-119. También en: Adorno, Th. W., «Musik im Rundfunk. Zwei unveröffentlichte Texte», en: Tiedemann, R. (ed.), Frakfurter Adorno Blätter, VII, 
Después de la investigación sobre la música en la radio, entre 1940 y 1942 Adorno participó activamente en el Film Music Project, financiado igualmente por la Rockefeller Foundation y dirigido por Hanns Eisler. El objeto del estudio era la relación entre el cine y la música, fijándose cuatro focos de atención: (1) La aplicabilidad fílmica de nuevos materiales y formas musicales. (2) Las cuestiones de instrumentación, considerando específicamente la realidad práctica de los procedimientos de registro. (3) Aspectos de la mezcla, de la relación entre el diálogo y la música, y de la utilización de efectos de sonido sintéticos y naturales. (4) Los estudios generales en el ámbito de la dramaturgia de la música de cine ${ }^{19}$. El informe final, redactado conjuntamente por Eisler y Adorno, se finalizó en 1944 y fue publicado tres años después, firmado sólo por Eisler, con el título Composing for the Films ${ }^{20}$. En el prólogo se remite, «a quien desee profundizar en las bases teóricas de la investigación sobre la composición para el cine», al capítulo "La industria cultural. Ilustración como engaño de masas» de Dialéctica de la Ilustración, publicada ese mismo año. El texto contiene, en su primer párrafo, una formulación sintética de las tesis que sustentaban aquella investigación, que son las que sustentaban el conjunto de los análisis de la teoría crítica en aquella época. Dice así:

El cine no puede entenderse de manera aislada como una forma artística específica, sino como el medio más característico de la cultura de masas contemporánea que emplea las técnicas de reproducción mecánica. La cultura de masas no ha de considerarse un arte original de las masas que se erige sobre ellas. Un arte así ha dejado de existir o no existe todavía. En los países industrializados se han extinguido hasta los vestigios de un arte popular espontáneo que, a lo sumo, sobrevive en zonas agrarias subdesarrolladas. En la era industrial avanzada, las masas no tienen más remedio que descansar y recomponerse como parte de la necesidad de regenerar la fuerza de trabajo que ellas mismas consumieron en el alienante proceso productivo. Esta es la única «base de masas» que tiene la cultura de masas. Sobre ella se asienta la poderosa industria del entretenimiento que siempre produce, satisface y reproduce nuevas necesidades. No es necesario decir que esta cultura de masas no es un producto del siglo xx; tan sólo se ha monopolizado y organizado a fondo ${ }^{21}$.

München, Text+Kritik, 2001, pp. 90-120.

19 Sobre el Film Music Project véase: VIEJo, B., Música moderna para un nuevo cine. Eisler, Adorno y el Film Music Project. Madrid, Akal, 2008. JAY, M., La imaginación dialéctica. Una historia de la Escuela de Frankfurt. op. cit., cap. VI.

20 Eisler, H., Composing for the Films. Nueva York, Oxford University Press, 1947. En 1969 Adorno publicó en Suhrkamp la "primera edición de la versión original», con una nota final dónde explica tanto el motivo de que en la primera edición americana apareciera sólo Eisler como autor, como las modificaciones que éste incluyó en 1949 en la edición realizada en Berlín Oriental. Vid. Adorno, Th. W.; EisLer, H., Komposition für den Film, en: GS 15, pp. 144-145.

21 Adorno, Th. W.; Eisler, H., Komposition für den Film, GS 15, p. 11. 
El análisis de la cultura en la época en que se habían industrializado sus productos debía comenzar, tal como Walter Benjamin había considerado imprescindible, por esclarecer cómo se habían hecho vigentes «en todos los campos de la cultura el cambio de las condiciones de producción» ${ }^{22}$. Para Adorno, por tanto, la cuestión no podía ser el carácter artístico o no del cine y de los nuevos productos de la cultura de masas, cuestión que se planteó muy pronto, en 1911, por parte del futurista italiano Ricciotto Canudo, cuando lo llamó «séptimo arte», una expresión que se mantiene hasta la fecha y quería afirmar la inclusión del cine en el panteón de las artes, y no como una más, sino como la síntesis de las artes del espacio y de las del tiempo, como «el arte total al que, desde siempre, han tendido todas las artes ${ }^{23}$. Si en el análisis de la música radiofónica se preguntaba por «las modificaciones internas que los fenómenos musicales en cuanto tales sufren al subordinarlos a la producción comercializada de masas», en el caso del cine, y la televisión, se trataba desde el principio de una producción mecanizada y estandarizada para un público que era, potencialmente, toda la población. Aún más, y de acuerdo con la intención declarado por la industria cultural, se trataba de conocer más y mejor los mecanismos operantes en el cine, la radio y demás medios, para conseguir una mayor satisfacción de los receptores como instrumento para conseguir una mayor adhesión a los propósitos de la industria en particular y de los dirigentes de la sociedad en general. Si esta industria cultural «siempre produce, satisface y reproduce nuevas necesidades», mediante la penetración en la estructura psíquica de los consumidores, entonces la teoría crítica de la sociedad debía ampliar sus recursos teóricos en dirección a Freud ${ }^{24}$.

Desde 1924, durante la preparación de su tesis de habilitación ${ }^{25}$, Adorno se había ocupado ya de la teoría psicoanalítica, pero a partir de 1934 los escritos de Freud no serán, de ninguna manera, una ocupación marginal, sino un apoyo teórico fundamental para ilustrar la dialéctica de la subjetivación en una totalidad dañada; para analizar críticamente el capitalismo desarrollado, cada vez más volcado en mantener el dominio no a través de la violencia directa, sino por el método mucho más económico y más efectivo de manipular los deseos

22 Benjamin, W., «Das Kunstwerk im Zeitalter seiner technischen Reproduzierbarkeit. Dritte Fassung», in: Benjamin, W., Gesammelte Schriften, Frankfurt, 1991, vol. I/2, p. 473. En adelante esta edición será citada con las siglas GS seguidas por el número de volumen y de página.

${ }_{23}$ Canudo, R., "La Naissance d'un sixième art - Essai sur le cinématographe», apud: Canudo, R., Manifeste des sept arts. Paris, Séguier, 1995.

${ }_{24}$ Martin Jay recalca la audacia que suponía proponer en los años treinta el «improbable matrimonio de Freud y Marx», en: La imaginación dialéctica, op. cit., cap. III, pp. 151-192. Sin embargo, la influencia de Freud sobre Adorno aún no ha sido objeto de estudios específicos, cf. Sherratt, Y., Adorno's Positive Dialectic. Cambridge, Cambridge University Press, 2002, p. 1. Sobre el tema vid.: Freitas, V., «Adorno e Horkheimer leitores de Freud», Remate de Males, 2010, 30.1, pp. 123-146.

25 Adorno, Th. W., «Der Begriff des Unbewußten in der transzendentalen Seelenlehre», en: GS 1, pp. 79-322. 
de los dominados ${ }^{26}$. Como más tarde quedará demostrado por la forma en que los regímenes autoritarios alcanzaron el poder, los nuevos medios masivos eran el instrumento adecuado para crear una nueva ideología, para influir no sólo sobre las consciencias de los individuos, sino, mejor aún, sobre sus pulsiones inconscientes. Freud ya había señalado que la distinción entre psicología individual y psicología social o colectiva no era una cuestión de "factor numérico», sino que "el individuo integrado en una masa experimenta, bajo la influencia de la misma, una modificación, a veces muy profunda, de su actividad anímica. Su afectividad queda extraordinariamente intensificada y, en cambio, notablemente limitada su actividad intelectual $\aleph^{27}$. La interpretación freudiana de la formación de la masa, sus características y la adhesión sumisa a ella por parte del individuo, intentará dar razón de este comportamiento irracional, incluso de individuos normalmente racionales. La idea nuclear es que «la estructura libidinosa de una masa se reconduce a la diferenciación entre el yo y el ideal del yo, y al doble tipo de ligazón así posibilitado: identificación, e introducción del objeto en remplazo del ideal del yo» ${ }^{28}$. Este será el esquema, aquí sólo apuntado, que Freud desarrolla específicamente en otros textos ${ }^{29}$ y que Adorno incorporará en sus análisis de la televisión. En un texto de 1946 Adorno dejaría constancia de la profundidad de la influencia de Freud, a la vez que profundizaría su posición respecto a la necesaria mediación entre sociología y psicología ${ }^{30}$.

En esta línea el proyecto de la radio fue un magnífico laboratorio para introducir categorías y explicaciones psicoanalíticas para diseñar la tarea empírica e interpretar sus resultados. Para explicar las diferencias entre la música ejecutada para oyentes, de carne y hueso, y la ejecutada para su grabación y posterior reproducción masiva, era preciso adentrarse en el mecanismo pulsional de gratificación y en este campo sólo el psicoanálisis era una ayuda crucial. Los análisis de contenido realizados en la investigación y los textos teóricos surgidos de ellos constituyen testimonios del crecimiento teórico en la aplicación del psicoanálisis a la investigación social empírica. En un ambiente académico en el que ya se había impuesto la administrative Research y una sociedad en la

26 Sobre esta cuestión vid.: Zamoira, J. A., «El enigma de la docilidad. Teoría de la sociedad y psicoanálisis en Th. W. Adorno», en: САвот, M. (ed.), El pensamiento de Theodor W. Adorno: balance y perspectivas. Palma de Mallorca, Edicions UIB, 2007, pp. 27-42. MaIso, J., «La subjetividad dañada: Teoría Crítica y psicoanálisis», Constelaciones. Revista de Teoría Crítica, 5, 2013, pp. 132-150.

27 Freud, S., «Psicología de las masas y análisis del yo», en: Freud, S., Obras completas, trad. J. L. Etcheverry. Buenos Aires, Amorrortu, 1992, vol. 18, p. 84.

28 Ibid, p. 123.

29 En Freud, S., «Introducción al narcisismo», en: Obras Completas, op. cit., vol. 14, pp. 90-91, puede encontrarse el desarrollo dinámico de las relaciones libidinosas del yo con el objeto y el ideal de yo.

30 Adorno, Th. W., «Die revidierte Psychoanalyse», in: Horkheimer, M.; Adorno, Th. W., Sociologica II. Reden und Vorträge. Frankfurt a.M., Europäische Verlagsanstalt, 1962, pp. 94112. Recogido en: GS 9.2, pp. 20-40. 
que se estaba expandiendo el revisionismo teórico iniciado por Erich Fromm y Karen Horney entre otros, las hipótesis planteadas por Adorno en la investigación eran, como poco, inauditas. En el Film Music Project se partía de la aparente naturalidad que había adquirido rápidamente el cine sonoro, en el cual los grandes y rápidos avances tecnológicos en la grabación y reproducción de la música y del cine no habían significado una mayor calidad de la música como banda sonora del cine. Aunque, por otra parte, la banda sonora está al servicio del éxito comercial, también afirma que «sólo cuando la banda sonora refleje un conocimiento exacto de cada secuencia en particular y tome consideración de su función especial en cada caso específico podrá esperarse de verdad una mejora de la música de cine $»^{31}$. El núcleo de la cuestión es otro: «La objeción principal de la industria del cine a las innovaciones objetivas de la música la determina el resultado en taquilla conformando una supuesta legitimación protocolaria de la voluntad del público. Bajo las circunstancias actuales resultaría ingenuo e inútil explicar a los adinerados que lo que importa no es el dinero, sino el arte»32. La formación de esa «voluntad del público», producida de forma estandarizada y legitimada como soberana por la ideología implícita en los productos de la industria cultural, y, por otra parte, la interiorización de aquel pseudorrealismo, según el concepto que surgirá en el análisis de la televisión, será precisamente el campo que debe ilustrarse con los conceptos y herramientas psicoanalíticas.

\section{LA INVESTIGACIÓN EMPÍRICA ACERCA DE LA TELEVISIÓN}

La primera referencia directa de Adorno a la televisión la encontramos en el capítulo dedicado a «La industria cultural» de Dialéctica de la Ilustración. Allí los autores se muestran totalmente en contra de la opinión presente en buena parte de la intelectualidad de la época en el sentido de que la disolución del modo de vida antiguo, por efecto de la masificación y tecnificación del orden cultural, no da lugar a un caos cultural, sino a una mayor integración entre sus diversos componentes y niveles. El cine, la radio, la televisión y los otros productos de la industria cultural trabajan en esa dirección ${ }^{33}$. La televisión era ya en la sociedad norteamericana de la década de 1950 uno de los dispositivos indispensables en cualquier hogar y una extendida y poderosa red de emisoras

\footnotetext{
31 Adorno, Th. W.; Eisler, H., Komposition für den Film, GS 15, p. 136.

32 Adorno, Th. W.; EisLer, H., Komposition für den Film, GS 15, p. 133.

33 «La televisión tiende a una síntesis de radio y cine, que está siendo frenada hasta que las partes interesadas se hayan puesto totalmente de acuerdo, pero cuyas posibilidades ilimitadas pueden ser elevadas hasta al punto por el empobrecimiento de los materiales estéticos que la identidad hoy apenas velada de todos los productos de la industria cultural podrá mañana triunfar abiertamente, como realización sarcástica del sueño wagneriano de la "obra de arte total"», Horkheimer, M., Adorno, Th. W., Dialéctica de la Ilustración. Fragmentos filosóficos, trad. J.J. Sánchez. Madrid, Trotta, 1998, p. 169.
} 
hacía llegar a todo el país los productos que se creaban de forma centralizada y estandarizada. Los resultados de las investigaciones sobre el cine son totalmente pertinentes en al análisis del efecto de la televisión sobre los individuos, pues «la nueva técnica difiere de la cinematográfica en que, a semejanza de la radio, lleva el producto a la casa de los consumidores» ${ }^{34}$. Investigar los mecanismos de la creación o modificación de la voluntad en y a través de la televisión y otros medios de la cultura de masas fue el proyecto llevado a cabo entre 1952 y 1953 financiado por la fundación que el doctor Friedrich Hacker había establecido en Beverly Hills (Los Angeles). A diferencia de las llevadas a cabo anteriormente, bajo el patrocinio de fundaciones ligadas a la industria, la Hacker Foundation se sostenía sobre la clínica psicoanalítica que el doctor Hacker había fundado al exiliarse de Austria y que, además de desarrollar su labor como psicoanalista, le permitiría profundizar en sus investigaciones propias sobre la agresión, campo en el que se constituiría en referente en los años posteriores. Las investigaciones en este centro podían, por consiguiente, definirse sin ambages encaminadas a estudiar la respuesta de los espectadores ante el material recibido por los medios, y estudiarlo siguiendo los patrones psicoanalíticos más pertinentes y no debiendo adoptar una metodología necesariamente cuantitativa. Tanto por el objetivo, como por el planteamiento teórico, esta investigación estaba en la línea que habían esbozado los miembros del Instituto de Investigaciones Sociales. No olvidemos que la primera gran investigación empírica promovida en Estados Unidos había tenido como objetivo «el individuo potencialmente fascista, alguien cuya estructura es tal que lo convierte en especialmente vulnerable a la propaganda antidemocrática $»^{35}$.

Simultáneamente a la de la televisión, Adorno dirigió otra investigación para la misma fundación, consistente en el el análisis de contenido de la columna de astrología de Los Angeles Times, material idóneo para «la investigación de la naturaleza y motivaciones de algunos fenómenos sociales de gran alcance, que encierran elementos irracionales de un modo particular, fundidos con lo que puede calificarse de pseudoracionalidad» ${ }^{36}$. Los resultados se publicaron en 1956 con el título The Stars down to Earth y fueron la base empírica del posterior ensayo titulado «Superstición de segunda mano» ${ }^{37}$, trabajos en el que es explícita la finalidad de «arrojar alguna luz sobre el patrón de interacción de las fuerzas racionales e irracionales dentro de los modernos movimientos de masas». Se trataba de elucidar los mecanismos de control de las energías pulsionales a través de los nuevos medios técnicos de los medios de comunicación de masas y su puesta al servicio de la dominación.

La investigación de la televisión tenía como objetivo específico determinar el «efecto potencial de la televisión, su influencia en diversas capas de la

34 Adorno, Th. W., «Prolog zum Fernsehen», en: GS 10.2, p. 508.

35 Adorno, Th. W., «Studies in the Authoritarian Personality», en: GS 9.1, p. 149.

36 Adorno, Th. W., «The Stars down to Earth. The Los Angeles Times Astrology Column. A Study in Secondary Superstition», en: GS 9.2, 14.

37 Adorno, Th. W., «Aberglaube aus zweiter Hand», en: GS 8, 147-176. 
personalidad del espectador ${ }^{38}$. Recogiendo lo dicho para el cine, se trataba de determinar el mecanismo utilizado por la televisión para, en palabras dirigidas al cine en Dialéctica de la Ilustración, «imprimir con letras de fuego su omnipotencia, como omnipotencia de sus amos, en el corazón de todos los desposeídos en busca de empleo, constituye el sentido de todas las películas, independientemente de la trama que la dirección de producción elija en cada caso ${ }^{39}$. Éste es el núcleo a dilucidar en el cine y la televisión, y no meramente cuestiones intraestéticas, como en Canudo, o únicamente psíquicas, como en Rudolf Arnheim ${ }^{40}$. Este objetivo se alcanza con un análisis crítico del medio, tal que de sus resultados permita señalar aquellos elementos que actúan contra la idea de un individuo autónomo y libre, aunque no nos digan nada de cómo debe ser tal individuo.

No se trata, pues, de una cuestión ni primaria ni exclusivamente estética. No pueden tratarse separadamente los aspectos sociales, técnicos y artísticos ${ }^{41}$, todos estos aspectos dependen uno de otro, interdependencia que es uno de los elementos distintivos de la cultura de masas. No cabe oponerla a una supuesta alta cultura o cultura verdadera, toda vez que la separación de la cultura respecto de la cultura popular comienza, a partir de finales del siglo XVII y principios del siglo xvIII, con la integración en un único sistema de la diversidad de materiales, medios y fines, que caracterizaban a las prácticas culturales antiguas, y cuyo apogeo será la unificación en el sistema de la «industria cultural». Tal vez la ópera de Mozart, La flauta mágica (de 1791), sea una de las últimas grandes obras en que se da una fusión de los diferentes niveles de la cultura (las clasificadas como high-y low-), aproximadamente de la misma época en que una pintura de Jean-Honoré Fragonard, titulada La lectora (1772), nos puede servir como representativa del momento en que se inicia la definitiva escisión entre ellos ${ }^{42}$.

El análisis de la televisión realizado por Adorno presupone que ya ha desaparecido aquella sociedad en la que era posible decir que los individuos se encontraban, interaccionando entre ellos, en un espacio de libre competencia, guiados cada uno por sus propios intereses. De acuerdo con el discurso de la

38 Adorno, Th. W., «How to Look at Television», en: The Quarterly of Film Radio and Television, Vol. VIII, 1954, p. 474.

39 Horkheimer, M., Adorno, Th. W., Dialéctica de la ilustración, op. cit., p. 169.

40 Arnheim, R., El cine como arte. Trad. de E. L. Revol. Barcelona, Paidós, 1986.

41 Adorno, Th. W., «Prolog zum Fernsehen», en: GS 10.2, p. 507.

42 Cf. Hursenn, A., Después de la gran división: modernismo, cultura de masas, posmodernismo, trad. P. Gianera. Buenos Aires, Adriana Hidalgo Editora, 2006, especialmente cap. 2, pp. 41-88. Cf. MaIso, J., «Dialéctica de la gran división: Theodor W. Adorno y los medios de masas», en: САвот, M. (ed.), El pensamiento de Theodor W. Adorno. Balance y perspectivas. Palma de Mallorca, Edicions UIB, 2007, pp. 193-206. Савот, M., «El descubrimiento moderno de la oralidad y los medios audiovisuales», en: Remate de Males, Sao Paulo (en prensa). 
ideología del «individualismo posesivo» ${ }^{43}$, cada individuo acude libremente al mercado donde es posible encontrar un punto de equilibrio entre la oferta y la demanda de mercancías para satisfacer así las demandas libremente asumidas. Se consiguiría de esta manera el bien colectivo, según la teoría de la «mano invisible» que gobierna el mercado. Pero en las sociedades capitalistas desarrolladas, la ilusión de la libre concurrencia de voluntades individuales se desvanece completamente ante la cerrazón de las sociedades férreamente estructuradas y en las que la tarea primordial para el individuo no es acudir al mercado para interaccionar con los otros individuos, sino ser admitido en un determinado grupo, con el consiguiente temor a ser rechazado por el grupo en el que pretende insertarse y construir su personalidad. El público, que en la primera fase de la cultura burguesa era un resultado de la configuración del espacio público que debía ordenar el encuentro de sensibilidades individuales ${ }^{44}$, es en la época del capitalismo monopolista un conjunto informe y atomizado de consumidores. El acceso a la interioridad de cada individuo particular se convierte en una necesidad del sistema productivo y de las instancias de control político, del primero para modelar los supuestamente libres deseos del consumidor, del segundo para desviar hacia respuestas políticamente controlables la frustración por la insatisfacción que provoca la imposibilidad de colmar los deseos estimulados. En esta situación la televisión tiene la capacidad y los mecanismos para realizar una función de dominio de los individuos, sobre todo gracias al mecanismo llamado por Leo Löwenthal un "psicoanálisis al revés». Esto es: mientras que la terapia psicoanalítica parte del síntoma perturbador para llegar a su causa oculta, con el fin de disolver el poder del trauma origen, la televisión tiende a «exaltar el mismo síndrome que es considerado por el psicoanálisis como un retorno a fases infantiles de desarrollo que el psicoanalista trata de disolver» ${ }^{45}$. Es posible la exaltación del síndrome gracias, por una parte, a ciertas características del medio televisivo y, por otra, a que el individuo está psíquicamente debilitado, más escindido que nunca entre sus diferentes energías y facultades, esto es, un cuadro de patologías psíquicas que «implican todos los mecanismos de consciente e inconsciente en que insiste el psicoanálisis» ${ }^{46}$.

43 Macpherson, C. B., The Political Theory of Possessive Individualism: From Hobbes to Locke. London, Clarendos Press, 1962. Trad. castellana de J. R. Capella, en: M.C.B., La teoría política del individualismo posesivo. Barcelona, Fontanella, 1970.

${ }_{44}$ Cf. Habermas, J., Strukturwandel der Öffentlichkeit. Untersuchungen zu einer Kategorie der bürgerlichen Gesellschaft. Neuwied/Berlin, 1962. Trad. castellana de A. Domènech, en: Historia y crítica de la opinión pública. La transformación estructural de la vida pública. Barcelona, Gustavo Gili, 1981.

45 Adorno, Th. W., «How to look Television», in: Bernstein, J. M. (ed.), Theodor W. Adorno, The Culture Industry. Selected essays on Mass Culture. London/New York, Routledge, 1981, p. 174.

46 Adorno, Th. W., "Television and the Patterns of Mass Culture», in: Rosenberg, B., Manning, D. (eds.), Mass Culture. The Popular Art in America. Nueva York, Free Press, 1957, p. 479. 


\section{Mecanismos y efEctos de la televisión}

El enorme éxito de la televisión se manifiesta, cincuenta años después de la investigación adorniana, en la omnipresencia de la pantalla en la experiencia cotidiana de las personas. "Ver» la pantalla de televisión, de cine o de ordenador, sea cual sea el contenido visto, se ha convertido en «normal» después de apenas un par de generaciones. Si recordamos lo sucedido a los espectadores de la exhibición «La llegada del tren», en 1895, es fácil concebir el alcance y efectividad del contenido y de la forma asimilado, interiorizado, de manera que el horror que pudiera causar entonces se ha convertido hoy en algo ni siquiera reseñable. El error de los primeros espectadores del cine no fue conferir realidad a las imágenes de la pantalla, sino no detectar un nuevo orden de ficción, otro «als ob», para el cual aún no habían sido entrenados ${ }^{47}$. La conversión en «normal» de la acción de ver en una pantalla, interpretar la percepción experimentada y ser influido, consciente e inconscientemente, se basa, en primer lugar, en convertir en invisibles los contornos de la pantalla, esto es: borrando el marco que separa el aparato de la realidad del mundo vivido; o sea: la industria cultural tiene por objetivo que lo que vemos sea tan real que la aceptemos como realidad y que ni siquiera nos apercibamos de ello. Este es el significado oculto en el eslogan de cualquier spot de autopromoción: la televisión como «una ventana al mundo» (se supone aquí que puedes asomarte a la ventana y nada interferirá tu experiencia directa del exterior). Benjamin escribió que "Aproximar", espacial y humanamente, las cosas hasta sí es para las masas actuales un deseo tan apasionado como lo es igualmente su tendencia a intentar la superación de lo irrepetible de cualquier dato al aceptar su reproducción ${ }^{48}$. Este deseo es satisfecho por la televisión cuando pone ante tus ojos el mundo entero y, de este modo, puedes estar en cualquier sitio y en cualquier momento sin levantarte del sillón. No nos interesan específicamente en este texto los conceptos o interpretaciones freudianas que moviliza Adorno en su interpretación, sino la detección y consiguiente análisis de los mecanismos propios de la televisión que permiten la creación de una ficción que, primero, no parezca serlo, y, segundo, se erija como primer referente de «realidad». Estos mecanismos, debidamente ocultos, son los que posibilitan que la industria cultural cumpla simultáneamente con las finalidades económicas y políticas, en este último caso: anular la capacidad de crítica y protesta del individuo explotado y dominado.

47 «La existencia de las técnicas visuales nos introduce en una nueva dimensión psicológica de la que nos resistimos a darnos cuenta. El razonamiento vale tanto para el cine como para la televisión, si se considera que en la recepción televisiva la fijeza hipnótica de quien está aislado entre la multitud que lo rodea en una sala de cine es corregida por las mayores posibilidades de distracción permitidas por la situación de quien se halla sentado en grupo, en el ambiente familiar, frente a la pequeña pantalla.» Eco, U., "Apuntes sobre la televisión», en: Íbid., Apocalípticos e integrados, trad. A. Boglar. Barcelona, Lumen, 1981 (6ª edición), p. 351.

48 Benjamin, W., "Das Kunstwerk im Zeitalter seiner technischen Reproduzierbarkeit», GS I/2, p. 479. 
Adorno analiza tres procedimientos usados en el medio televisivo para conseguir el conjunto de fines propuestos por la industria cultural, a saber: adiestrar al espectador en una interpretación de las imágenes y sonidos que aparecen en pantalla; que la percepción sea placentera emocionalmente e intelectualmente armonizante; y que prometa más gratificaciones en el futuro. Objetivos que podrían resumirse en uno: rebajar al individuo a la existencia unidimensional de trabajo productivo y consumo de mercancías. Dichos procedimientos pueden enunciarse bajo tres epígrafes: 1) la diferenciación entre diferentes tipos de producto audiovisual, 2) el pseudorrealismo, 3) la construcción de clichés.

La producción de mercancías en la industria cultural se organiza en un número limitado de «géneros» (informativos, cine, música, etc.), cada uno subdividido en subgéneros (cine: comedia, western, policíaco, etc.) y cada uno con temas, medios y lenguajes específicos. Esta organización permite: a) clasificar los consumidores en grupos según su nivel de consumo de uno u otro género, y b) gratificar al consumidor ofreciéndole lo que él espera consumir, y no por ser su "gusto", sino porque ha sido adiestrado en un género que se repite en cada uno de sus ejemplares. En una «película de...» cabe esperar cierto tipo de desarrollo, cierto tipo de situaciones y ciertos desenlaces. Cada género preestablece también la pauta de las actitudes posibles para el espectador, siendo unos productos adecuados para recepciones más o manos dispersas y desconcentradas según sea la situación en que se encuentre dicho espectador. La producción de mercancías culturales por parte de la industria cultural es semejante a la organización de cualquier otra rama de la producción en el capitalismo avanzado. Lo que distingue el funcionamiento de la industria cultural es que la especialización de la producción, necesaria en un régimen de división del trabajo y estandarización del mismo, no deriva, en el caso de la industria cultural, de las características de la materia prima o de los medios de producción a emplear, sino de la especialización del psiquismo de los receptores, esto es: de las necesidades que se le han creado. Organización psíquica que promueve la misma industria para así poder garantizarse los dos objetivos mencionados de clasificar y gratificar. Los argumentos adornianos sobre la posibilidad real que tiene la industria cultural de imponer un determinado catálogo de «necesidades» se apoyan en los análisis freudianos. No sólo en aquellos que, como el ya citado, interpretan la formación y estructura psíquica de las masas, sino también en aquellos que interpretan dinámicamente el traspaso de energía libidinal de esas masas a objetos determinados ${ }^{49}$.

En segundo lugar, Adorno habla de pseudorrealismo de la televisión en el sentido de que los contenidos audiovisuales en pantalla se producen para ser una representación fidedigna de la realidad exterior al marco de la pantalla del televisor, de acuerdo con aquel eslogan de la «ventana al mundo». Es falso en tanto que el objetivo realmente pretendido es «representar la realidad» no

49 Freud, S., «Formulaciones sobre los dos principios del acaecer psíquico», en: Obra Completa, op. cit., vol. 12, pp. 223-231. 
lo más fidedignamente posible, sino de la forma que más satisfaga a la masa de espectadores. Apunta directamente a esclarecer el mecanismo de construcción, en el medio televisivo, de un imaginario lo suficientemente potente para que pueda convertirse en la ficción hegemónica, esto es, en la interpretación canónica, socialmente aceptada, de la multiplicidad sensorial producida por el medio o mecanismo. Walter Benjamin ya había llamado la atención sobre el método de condicionamiento que se pone en marcha en el cine y que es igualmente válido para la televisión. A partir de la segunda década del siglo xx la concepción psicológica de la percepción debe abandonar el realismo ingenuo que dominaba hasta entonces. De acuerdo con la contemporánea teoría de la Gestalt, y dado el inevitable carácter secuencial del cine, Benjamin notaba que «la concreta comprensión de cada imagen individual aparece prescrita por la secuencia de las precedentes $»^{50}$. Las experiencias previas del espectador condicionan las experiencias futuras del mismo espectador. Si aprendemos a interpretar las imágenes y sonidos de la pantalla gracias a las indicaciones que, a través de la pantalla, nos transmite el mismo mecanismo que las produce, entonces no sólo aprendemos la continuidad de la narración, sino que también aprendemos los esquemas abstractos o modelos que remiten a un determinado contenido. A ello se refiere Benjamin cuando dice de la cámara que registra: «sólo gracias a ella sabemos algo del inconsciente óptico, lo mismo que del inconsciente pulsional gracias al psicoanálisis» ${ }^{51}$. El realismo del cine y la televisión no se debe a que cine y televisión «sean una ventana al mundo», sino a que el único mundo que vemos es el que nos llega a través de la pantalla de televisión, previamente fabricada por un mecanismo ${ }^{52}$. No se trata de características idiosincrásicas o «defectos psíquicos» individuales, sino de una característica esencial del medio. De la tesis fundamental de Rudolf Arnheim, según la cual el carácter artístico del cine deriva directamente de su poco realismo ${ }^{53}$, debe inferirse inmediatamente que el carácter creativo en el medio consiste en crear esquemas o clichés que permitan considerar como real algo que es una ficción. Es todo el mecanismo el que crea un mundo, en el que los objetos son iguales a si mismos, reconocibles, por tanto, como aquello que «debe ser».

Por último, analiza el mecanismo por el cual en la televisión puede transmitirse de forma latente un contenido incluso superior al de las imágenes manifiestas, utilizando las diferentes técnicas cinematográficas. De esas técnicas dio cuenta Sigfried Kracauer en su Teoría del cine, subtitulada precisamente

50 Benjamin, W., «Das Kunstwerk im Zeitalter seiner technischen Reproduzierbarkeit», GS I/2, p. 485.

51 Benjamin, W., «Das Kunstwerk im Zeitalter seiner technischen Reproduzierbarkeit», GS I/2, p. 500 .

52 Esta idea se encuentra ya en 1932, en Brave New World de Aldous Huxley, se repite en 1948 con 1984 de George Orwell y, más tarde, pasa de la literatura distópica a los análisis sociológicos. Vid. Barnsley, J. H., «Huxley on television». Society, 19 (1981), pp. 63-65.

53 ARnheIm, R., op. cit., p. 19. 
«La redención de la realidad física ${ }^{54}$. El contenido latente está construido por clichés o estereotipos que explican fácil y satisfactoriamente cualquier situación que pueda darse en la experiencia cotidiana del espectador y conectarla con experiencias cotidianas del mismo individuo. La repetición de caracteres, situaciones y conclusiones en los productos ayuda en el aprendizaje forzado de la gramática de significación del medio, a la vez que reduce los costes de producción y permite un mensaje latente que facilite la disciplina social mediante una concreta disciplina individual. La distinción entre contenido explícito y contenido latente en la televisión, dirá Adorno, se exacerba dirigiéndose cada uno de ellos al nivel adecuado de la estructura de personalidad. Esto funcionaba igualmente en el llamado arte autónomo, pero en este caso esta estructura multicapa se fusionaba en una unidad, compleja y rica, que daba a la obra de arte su carácter único y potencialmente liberador. La televisión, en cambio, no deja lugar para el libre juego de imaginación y razón, momento liberador, sino que estructura los estímulos en función de las respuestas deseadas. Los estudios sobre autoridad y familia habían establecido que sólo una conciencia sumisa ante la injusticia puede mantenerse disciplinada ante la injusticia objetiva y flagrante que se presenta ante nuestros ojos. Conseguir esa sumisión es, en la mayoría de ocasiones, la tarea que realiza el contenido latente de la producción televisiva. Procedimientos que se utilizan a este fin son, por ejemplo, la normalización (y banalización) del delito; la transgresión en la ficción de las rígidas normas sociales, con la consiguiente satisfacción que dicha ficticia transgresión comporta; o la aceptación como hechos inevitables de la naturaleza lo que no son más que consecuencias de acciones humanas, con la gratificación subsiguiente al librarse al espectador de toda responsabilidad. Además de lo que había señalado el psicoanálisis freudiano acerca de la represión necesaria para hacer frente a ese sentimiento de culpabilidad, y que pueda transformarse en placer sádico contra las víctimas, Adorno destacará posteriormente otro aspecto de la cuestión: la conexión entre el medio de reproducción audiovisual y el cuadro de frialdad burguesa, esto es, la frialdad del espectador ante el horror, mostrando la ambivalencia de la actitud, pues «lo que hay de inhumano en la capacidad de distanciarse y elevarse como un espectador, viene a ser a fin de cuentas lo humano, pese a toda resistencia de sus ideólogos» ${ }^{55}$.

El análisis de los aspectos sociales, técnicos y artísticos de la televisión, considerados en su dependencia mutua y con la ayuda de la psicología profunda, muestra que "la televisión es un problema cultural y pedagógico» ${ }^{56}$, frase que nos servía de lema al principio del texto. El análisis efectuado por Adorno está guiado por el interés emancipatorio del individuo: los poderosos reprimen las objetivas ansias de liberación de los oprimidos y necesitan para ello deshumanizarlas: la ilustración sólo debe darse cuando sea necesaria y en aquello que

54 Kracauer, S., Teoría del cine: la redención de la realidad física, trad. de J. Homero. Barcelona, Paidós 1989.

55 Adorno, Th. W., Negative Dialektik, GS 6, p. 356.

56 Adorno, Th. W., «Television and the Patterns of Mass Culture», op. cit., 487. 
sea necesaria para la reproducción del modo de producción, pero no en aquello que represente una liberación para el individuo de las coerciones naturales y sociales, en este sentido la televisión reúne las condiciones para ser el mecanismo más refinado de lo que llamó semiformación ${ }^{57}$. Tenemos así el modelo de una vida dañada en la totalidad falsa, la frialdad burguesa como la forma de soportar seguir viviendo después del horror y aunque con ello se alimenten las condiciones para que pueda reproducirse lo que significó Auschwitz ${ }^{58}$.

\section{RELACIÓN DE LOS MECANISMOS ACTUALES DE SOCIALIZACIÓN Y LA SEMIFORMACIÓN AUDIOVISUAL}

La tarea que sigue atribuyéndose a la escuela, que podemos leer, por ejemplo, en la constitución de la UNESCO, es la de potenciar la educación, la autonomía y la formación integral del individuo, toda vez «que la amplia difusión de la cultura y la educación de la humanidad para la justicia, la libertad y la paz son indispensables a la dignidad del hombre y constituyen un deber sagrado que todas las naciones han de cumplir con un espíritu de responsabilidad y de ayuda mutua ${ }^{59}$. Esta declaración de principios se deriva directamente de la Declaración Universal de los Derechos Humanos aprobada en 1945 y que entroncaba con el programa de la burguesía revolucionaria que latía tras la Declaración de los Derechos del Hombre y del Ciudadano de 1789 o la Declaración de Derechos de Virginia de 1776, esto es: supone la idealización de unos individuos y de una sociedad hace más de dos siglos. Para cumplir con la tarea asignada la escuela se encuentra, en el presente, en una posición muy distinta de la que suponían los reformadores ilustrados del siglo xvIII: aunque institucionalmente se le sigue confiando en exclusiva la competencia de educar a los nuevos individuos, de hecho está perdiendo, desde hace varias décadas, la hegemonía como institución socializadora y formativa.

La colonización de la vida cotidiana por la presencia de la televisión es la muestra de que es la primera fuente de socialización de los jóvenes, con mayor influencia y poder de penetración que los entornos clásicos: la escuela y la familia. En este cambio han aparecido multitud de síntomas que son sólo la manifestación de perturbaciones en el desarrollo considerado «normal» hasta aquel momento. Muchos de ellos muestran una nada sorprendente analogía con los sucedidos cuando la escritura desplazó a la oralidad como canal

57 Adorno, Th. W., «Theorie der Halbbildung», in: GS 8, pp. 93-121.

58 Adorno, Th. W., Minima Moralia. Reflexionen aus dem beschädigten Leben. GS 4, p. 83 [§ 46]; Ibid., "Notas marginales sobre teoría y praxis», GS 10.2, p. 691; Ibíd., Negative Dialektik, GS 6, p. 350-399. Zamora, J.A., «Filosofía después de Auschwitz», en: NudLer, O. (ed.), Filosofía de la filosofía. Madrid, Trotta, 2010, pp. 173-213.

59 Preámbulo de la constitución de la Organización de las Naciones Unidas para la Educación, la Ciencia y la Cultura, aprobada en Londres el día 16 de noviembre de 1945 [disponible en: http://portal.unesco.org, consulta: 31/8/2014]. 
hegemónico de transmisión de información y de experiencias ${ }^{60}$. Todo junto nos lleva al análisis que en 1933 Benjamin emprendió sobre la experiencia y que se hacía visible como una ruptura de la tradición, en el momento en que la reproductibilidad técnica ya había alcanzado el corazón de la vida cotidiana de los humanos ${ }^{61}$. La alfabetización audiovisual y digital, que a finales del siglo xx fue impulsada desde los poderes públicos, presuponía que las llamadas nuevas tecnologías de la información y de la comunicación (TIC) eran aliados o instrumentos útiles para la consecución de los tradicionales objetivos de la escuela, tanto de aprendizaje como de socialización ${ }^{62}$. Una vez que esta etapa se ha cumplido ya en los países económicamente más ricos, sería preciso recordar el análisis de Adorno, pues nos permitiría plantearnos estrategias ante dos de sus conclusiones, que por lo dicho consideramos aspectos esenciales en la cuestión de la formación. 1) Que la diferencia entre el modelo socializador de las primeras sociedades modernas, canalizado a través de las familias y la escuela, en las sociedades capitalistas desarrolladas es «más el producto de sus pares en un sentido caracterológico; esto es, en términos sociológicos, de sus "grupos pares", los otros chicos en la escuela o en la manzana» ${ }^{63}$. 2) Estos últimos modelos son accesibles fundamentalmente mediante la televisión, no en el trato directo como sucedía con la familia y la escuela. Consecuentemente las características de personalidad en uno y otro contexto son diferentes, y esto se muestra en que, en la fase del mercantilismo, se potenciaban actitudes como la concentración, el esfuerzo intelectual y la erudición (en el sentido de acumulación de conocimientos), actitudes puestas en práctica en el trabajo intelectual de lectura y escritura, y que se ajustaban tanto a las necesidades económicas del sistema, como a los principios políticos que lo justificaban. Estos modelos se sustituyen en cuanto la referencia ya no es una autoridad que debe interiorizarse, sino que se trata de pertenecer (o no) a un grupo social muy determinado. En este nuevo esquema de socialización las características de personalidad individual que más se ajustan ya no son las mencionadas, correspondientes a la época del puritanismo, sino las del individuo en constante peligro de perder su identidad si es expulsado del grupo caracteriológico en el que está integrado.

60 A esta cuestión dedicamos "Cultura digital de masas y "nueva educación" ", Impulso, vol. $23, \mathrm{n}^{\circ} 57,2013$, pp. 19-28, y «El "descubrimiento moderno de la oralidad" y los medios audiovisuales», Remate de Males, [en prensa].

${ }_{61}$ Cf. Benjamin, W., «Erfharung und Armut», in: GS II/1, pp. 213-219; Amengual, G.; САвот, M.; Vermal, J. (eds.), Ruptura de la tradición. Estudios sobre Walter Benjamin y Martin Heidegger. Madrid, Trotta, 2008.

62 Incluso Umberto Eco erraba en eso en 1965: «La civilización de la televisión como complemento a una civilización del libro. Es quizás menos difícil que lo que se cree, y no sería desacertado proponer a la televisión una serie de transmisiones didácticas encaminadas a "descondicionar" al público, a enseñar a no contemplar la televisión más de lo necesario, a dominar e identificar por uno mismo el momento en que la escucha ya no es ya voluntaria, en que la atención se hace hipnosis, la convicción asentimiento emotivo.» (op. cit., p. 379).

63 Adorno, Th. W., «Television and the Patterns of Mass Culture», op. cit., p. 476. 


\section{Conclusiones}

Partíamos en este texto del diagnóstico de Adorno según el cual «la televisión presenta un problema cultural y pedagógico». Del análisis de su argumentación concluimos que la televisión es, por su misma estructura, un mecanismo que propicia lo que designó con el término «semiformación»(Halbbildung). En un texto anterior argumentamos que el núcleo de la crítica de Adorno a la «industria cultural» era que estaba estructuralmente organizada para provocar una regresión psíquica en los individuos de la masa, para hacerlos más dóciles y manipulables ${ }^{64}$. De los análisis de la televisión realizados por Adorno descubrimos la profundidad de la adopción de conceptos y presupuestos freudianos para analizar el efecto de dicha televisión sobre los individuos convertidos en masas. Quedarían por analizar cuestiones muy concretas de ese maridaje tan profundo entre Freud y Adorno, pues este es un tema que sólo recientemente ha adquirido especificidad ${ }^{65}$. Son precisas, pues, investigaciones que lean a Adorno con esta hipótesis: es Freud quien influye decisivamente en la formación de la dialéctica negativa; la insistencia adorniana en la idea de lo no idéntico es una muestra del problema teórico. Las investigaciones en este campo deberían incluir asimismo las investigaciones realizadas desde la práctica clínica psicoanalítica. Estos análisis servirán para conocer mejor los mecanismos concretos con los que se articula actualmente la educación, esto es: los procesos de formación de individuos socializándose en un medio colonizado por la televisión. También servirán para ver el alcance de penetración de este medio y que su estructura intrínsecamente perversa es monolítica o es posible detectar lugares sobre los que actuar críticamente. Adicionalmente, aún podrían extraerse argumentos para la discusión sobre aquello que constituye el carácter artístico, esto es, aquello que, según Adorno, diferencia una mercancía de la cultura de masas y una obra de arte, una vez que se han vuelto perceptivamente indiscernibles. Creemos que la argumentación que realiza en «Transparencias cinematográficas» ${ }^{66}$ nos permitiría arrojar luz sobre el tema, pues este texto puede leerse como un ensayo, por parte de Adorno, de responder a la anterior cuestión, toda vez que en el cine, a pesar de ser un producto y un instrumento de la industria cultural más poderosa, puede abrirse una brecha para volverlo un instrumento con una finalidad de ilustración.

Universitat de les Illes Balears

Mateu CaBot

mateucabot@gmail.com

[Artículo aprobado para publicación en diciembre de 2015]

64 Савот, M., «La crítica de Adorno a la cultura de masas», Constelaciones. Revista de Teoría Crítica, vol. 3, 2011, pp. 130-147 [Disponible en http://www.constelaciones-rtc. net/03/03_07.pdf Consulta: 1/09/2014]

65 Sherratt, Y., Adorno's Positive Dialectics. Cambridge, Cambridge Univesity Press, 2002, p. 1.

66 Adorno, Th. W., «Filmtransparente», GS 10.1, pp. 353-361. Cf. MaIso, J.; VIEJo, B., "Imágenes en negativo. Notas introductorias a "Transparencias cinematográficas” , Archivos de la filmoteca, 2006, 52, pp. 121-129. 